\title{
Penerapan Knowledge Management System Pada Bidang Pelayanan Di SMA Satria Nusantara
}

\author{
Gunawan $^{1}$, Merry Agustina $^{2}$, Suzi Oktavia Kunang ${ }^{3}$ \\ 1,2,3Information System Departement, Universitas Bina Darma, Palembang, Indonesia \\ Email: 1gunawangunawan677@gmail.com, 2merry_agst@binadarma.ac.id, \\ ${ }^{3}$ suzi_oktavia@binadarma.ac.id
}

\begin{abstract}
Abstrak
Perkembangan teknologi dewasa ini telah menjangkau hampir semua elemen dalam kehidupan manusia tidak terkecuali dalam dunia pendidikan. SMA Satria Nusantara merupakan suatu instansi pendidikan yang bertugas untuk mendukung dan menyediakan pendidikan yang berkualitas guna memberi manfaat dalam mencerdaskan anak bangsa Pelayanan akademik yang berjalan saat ini di SMA Satria Nusantara melibatkan bagian-bagian kerja dimana masing-masing bagian akan melakukan pelayanan siswa berdasarkan prosedur kerja yang berlaku di sekolah dan tugas tanggung jawab sesuai dengan jabatan di bidang kerjanya masing-masing, Bidang pelayanan yang ada di SMA Satria Nusantara antara lain pelayanan pendaftaran siswa baru, pelayanan pembayaran iuran SPP dan pembangunan, pelayanan prosedur pengambilan dan legalisir ijazah, Pelayanan administrasi sekolah dan pelayanan bimbingan konseling. Dalam mengelola pengetahuan yang ada, masih ditemukan masalah yaitu masih sulitnya menyimpan pengetahuan untuk memberikan informasi kepada pengguna layanan, seperti layanan terhadap pendaftaran siswa baru, pelayanan prosedur pengambilan ijazah dan legalisir, pelayanan administrasi sekolah dan pelayanan bimbingan dan konseling. Untuk itu dibutuhkan tempat untuk menyimpan pengetahuan yang sudah ada agar bisa di gunakan untuk waktu yang panjang baik terhadap para siswa, staff guru dan karyawan, untuk menciptakan pengetahuan yang berhubungan dengan pelayanan siswa baik dari segi cara pelayanan maupun cara mendapatkan solusi, dan bagaimana memperbaharui pengetahuan yang sudah ada ataupun menambahkan pengetahuan baru yang berhubungan dengan pelayanan yang ada di SMA Satria Nusantara. Pada Sistem Knowledge Management System di bidang pelayanan siswa ini yang akan di bangun nantinya akan terdapat forum diskusi yang dapat digunakan seluruh siswa, guru dan staff karyawan dalam mengolah dan mendapatkan pengetahuan yang dibutuhkan, untuk menyelesaikan masalah bidang pelayanan.
\end{abstract}

Kata Kunci: Sistem, Informasi, Knowledge Management System 


\section{Journal of Software Engineering Ampera}

Vol. 1, No. 1, February 2020 e-ISSN: 2775-2488

https://journal-computing.org/index.php/journal-sea/index

\section{PENDAHULUAN}

Perkembangan teknologi dewasa ini telah menjangkau hampir semua elemen dalam kehidupan manusia tidak terkecuali dalam dunia pendidikan. Perkembangan teknologi juga berdampak pada persaingan institusi pendidikan atau sekolah untuk mewujudkan kualitas pendidikan yang tinggi. Pendidikan merupakan kunci utama dalam kehidupan untuk mencapai semua tujuan yang diinginkan. Dengan meningkatnya kualitas pendidikan maka akan meningkat pula kemampuan sumber daya manusia yang ada dalam meningkatkan taraf hidup yang dimilikinya.

Untuk dapat menciptakan sumber daya manusia yang unggul dan kompetitif perlu ditunjang oleh institusi pendidikan atau sekolah yang berkualitas. Untuk menciptakan kualitas yang diinginkan tersebut maka sekolah diharapkan dapat memberikan suatu layanan yang maksimal kepada para peserta didik dengan memanfaatkan teknologi informasi. Penggunaan teknologi informasi oleh sebuah organisasi tidak hanya mengacu pada pencarian informasi, namun mengarah pada kebutuhan pencarian pengetahuan (knowledge) karena pengetahuan dianggap sebagai sebuah sumber atau asset yang mempunyai peranan penting.

SMA Satria Nusantara yang beralamat di jalan Palembang-Jambi Km 67,5 Kec. Betung Kabupaten Banyuasin, merupakan suatu instansi pendidikan yang bertugas untuk mendukung dan menyediakan pendidikan yang berkualitas guna memberi manfaat dalam mencerdaskan anak bangsa. Pelayanan akademik yang berjalan saat ini di SMA Satria Nusantara melibatkan bagianbagian kerja dimana masing-masing bagian akan melakukan pelayanan siswa berdasarkan prosedur kerja (SOP) yang berlaku di sekolah dan tugas tanggung jawab sesuai dengan jabatan di bidang kerjanya masing-masing, bidang pelayanan yang ada di SMA Satria Nusantara antara lain pelayanan pendaftaran siswa baru, pelayanan pembayaran iuran SPP dan pembangunan, pelayanan prosedur pengambilan dan legalisir ijazah, Pelayanan administrasi sekolah danpelayanan bimbingan konseling.

Masalah yang dihadapi Sekolah SMA Satria Nusantara dalam mengelola pengetahuan yang ada, masih ditemukan masalah yaitu masih sulitnya menyimpan pengetahuan untuk memberikan informasi kepada pengguna layanan, seperti layanan terhadap pendaftaran siswa baru, pelayanan prosedur pengambilan ijazah dan legalisir, pelayanan administrasi sekolah dan 


\section{Journal of Software Engineering Ampera}

Vol. 1, No. 1, February 2020 e-ISSN: 2775-2488

https://journal-computing.org/index.php/journal-sea/index

pelayanan bimbingan dan konseling. Oleh karena itu dibutuhkan tempat untuk memelihara pengetahuan yang sudah ada, agar bisa di gunakan pada waktu yang panjang baik terhadap para siswa, staff guru dan karyawan, bagaimana menciptakan pengetahuan yang berhubungan dengan pelayanan siswa baik dari segi cara pelayanan maupun cara mendapatkan solusi, dan bagaimana memperbaharui pengetahuan yang sudah ada ataupun menambahkan pengetahuan baru yang berhubungan dengan pelayanan yang ada di SMA Satria Nusantara.

Sistem Knowledge Management Systemdi bidang pelayanan siswa ini merupakan solusi yang tepat untuk menjawab masalahtersebut. Knowledge Management System merupakan sistem informasi berbasis pengetahuan yang mendukung kreasi, pengaturan dan penyebaran dari ilmu pengetahuan kepada para manajemen dalam suatuorganisasi secara keseluruhan.Denganfitur yang tersediapadaKnowledge Management System, di harapkan mempermudah para siswa, guru dan staff karyawan dalam mengolah pengetahuan dan menjadi wadah untuk sharing antar siswa, staff guru dan karyawan. Berdasarkan permasalahan pada penjabaran di atas, maka dapat ditarik judul yaitu "Penerapan Knowledge Management System pada bidang pelayanan siswa di SMA satria Nusantara".

\section{METODOLOGI PENELITIAN}

\subsection{Metode Pengembangan Sistem}

Metode pengembangan system yang akan digunakan pada implementasi knowledge management system pada SMA Satria Nusantara ini adalah Metode Pemodelan atau Prototyping, suatu siklus dalam pengembangan sistem yang dilakukan secara keseluruhan. (Utomo, 2005). Tahap-tahap sebagai berikut. :

1) Pengumpulan Kebutuhan

2) Membangun Prototyping

3) Evaluasi Prototyping

4) Mengkodekan Sistem

5) Menguji Sistem

\subsubsection{Knowledge management}

Knowledge management adalah pendekatan-pendekatan sistematik yang membantu mengalirkan informasi dan pengetahuan kepada orang yang tepat pada saat yang tepat agar menciptakan sebuah nilai. Menurut Paul L Tobing (2007) ada dua jenis knowledge yaitu explicit knowledge dan tacit knowledge. 


\section{Journal of Software Engineering Ampera}

Vol. 1, No. 1, February 2020 e-ISSN: 2775-2488

https://journal-computing.org/index.php/journal-sea/index

Explicit knowledge merupakan segala bentuk knowledge yang sudah direkam dan dokumentasikan sehingga lebih mudah untuk didistribusikan dan dikelola. Sedangkan tacit knowledge merupakan knowledge yang terletak di dalam pikiran (otak) atau melekat di dalam diri seseorang yang diperolehnya melalui pengalaman dan pekerjaannya.

\subsection{Knowledge Management System}

Menurut O'Brien (2015), Knowledge Management Systems merupakan sistem informasi berbasis ilmu pengetahuan (knowledge) yang dapat mendukung hasil cipta (kreasi), pengaturan dan penyebaran dari ilmu pengetahuan bisnis kepada para pekerja dan manajer perusahaan.Tidak berbeda jauh dengan definisi yang dikemukakan oleh O'Brien. Turban et al. (2011) mengemukakan bahwa knowledge management system merupakan sistem informasi berbasis pengetahuan yang mendukung kreasi, pengaturan dan penyebaran dari ilmu pengetahuan bisnis kepada para pekerja dan manajer dalam perusahaan secara keseluruhan. Berdasarkan pengertian KMS diatas maka dapat disimpulkan bahwa KMS merupakan alat yang ditunjukan untuk mendukung sebuah strategi perusahaan dalam mengumpulkan, mengidentifikasikan, memilih, mengolah dan menyebarkan knowledge yang ada, baikindividual knowledge maupun knowledge perusahaan sehingga dapat mendorong pembelajaran dalam organisasi serta terciptanya berbagi pengetahuan antar karyawan

\subsection{Arsitektur KMS (Knowledge Management Systems)}

Arsitektur KMS dirancang untuk menangkap knowledge dan memungkinkan proses knowledge management menjadi efektif dan efisien. Gambar berikut ini menjelaskan arsitektur dari Knowledge Management System pada umumnya, dan dilengkapi dengan Gambar 2.1 dengan komponen- komponen yang terdapat pada arsitektur Knowledge Management System.

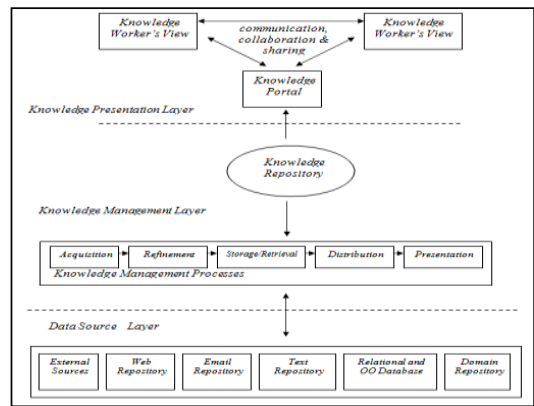

Gambar 1. Arsitektur Knowledge Management System (Probst et al. 2010). 


\section{Journal of Software Engineering Ampera}

Vol. 1, No. 1, February 2020 e-ISSN: 2775-2488

https://journal-computing.org/index.php/journal-sea/index

\section{HASIL DAN PEMBAHASAN}

\subsection{Pemodelan Sistem}

Use Case Diagram digunakan untuk memperlihatkan hubungan-hubungan yang terjadi antara aktor-aktor dengan use case-use case yang ada dalam sistem, sehingga calon pengguna sistem/perangkat lunak mendapatkan pemahaman tentang sistem yang akan dikembangkan. Use case diagram terdiridari 4 bidang pelayanan meliputi pelayanan pendaftaran siswa baru, pelayanan pembayaran iuran SPP dan pembangunan, pelayanan prosedur pengambilan dan legalisir ijazah, pelayanan bimbingan dan konseling.

1. Pelayanan Pendaftaran Siswa Baru, Pada use case diagram dibawah ini terdiri dari 2 aktor siswa dan guru kesiswaan, yang menjelaskan alur proses dalam bidang pelayanan Pendaftaran Siswa Baru

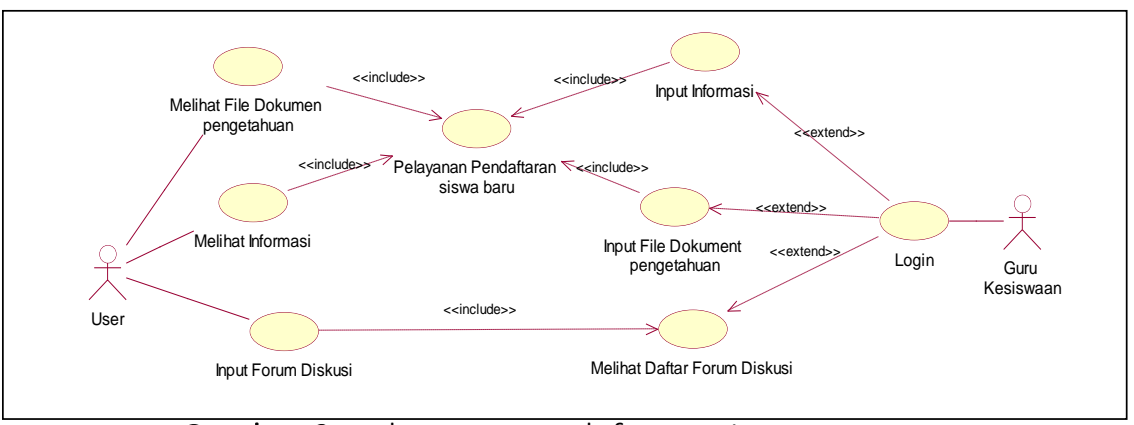

Gambar 2. Pelayanan Pendaftaran Siswa Baru

2. Pelayanan Pembayaran Iuran dan Pembangunan. Pada use case diagram dibawah ini terdiri dari 2 aktor siswa dan staf bendahara, yang menjelaskan alur proses dalam bidang pelayanan pembayaraniurandan SPP.

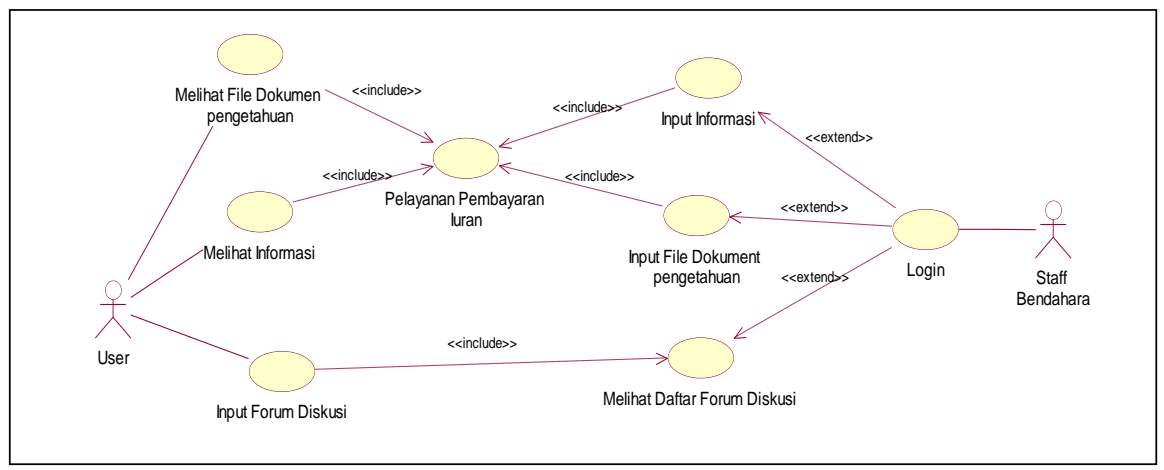

Gambar 3. Pelayanan Pembayaran Iuran dan Pembangunan 


\section{Journal of Software Engineering Ampera}

Vol. 1, No. 1, February 2020 e-ISSN: 2775-2488

https://journal-computing.org/index.php/journal-sea/index

3. Pelayanan Pengambilan Ijazah dan Legalisir, Pada use case diagram dibawah ini terdiri dari 2 aktor siswa dan tata usaha, yang menjelaskan alur proses dalam bidang pelayanan Pengambilan ljazah dan legalisir.

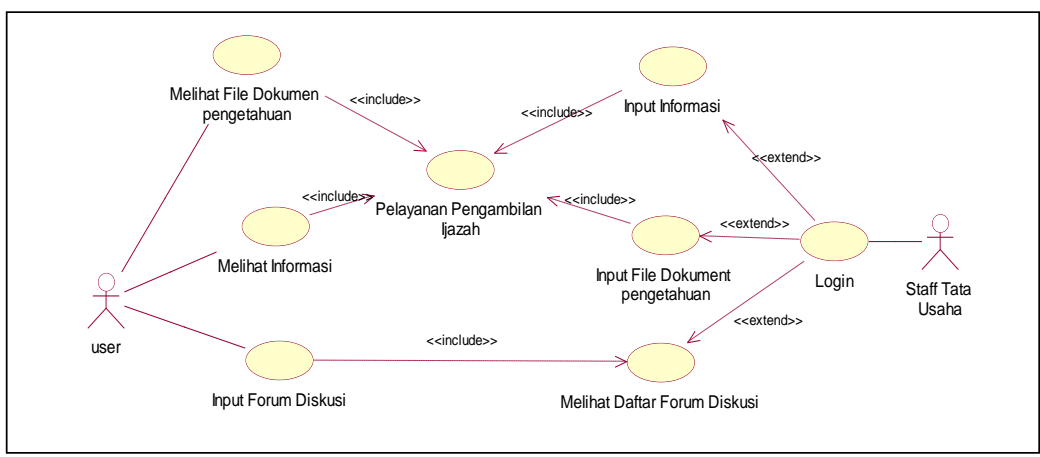

Gambar 4. Pelayanan Pengambilan Ijazah dan legalisir

4. Pelayanan Bimbingan dan konseling, Padause case diagram dibawah ini terdiri dari 2 aktor siswa dan guru bk, yang menjelaskan alur proses dalam bidang pelayananBimbingandanKonseling.

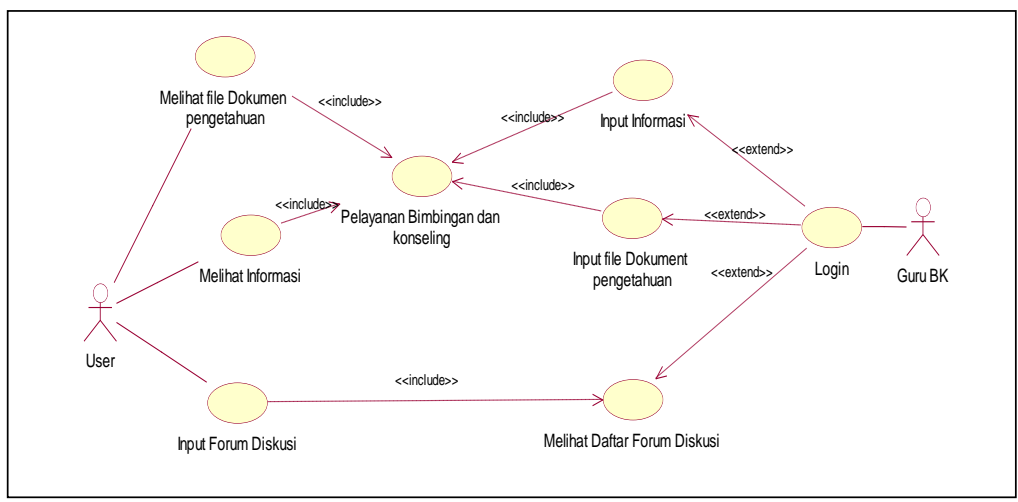

Gambar 5 Pelayanan Bimbingan dan Konseling

\subsection{Pengembangan Sistem}

Berdasarkan tahapan-tahapan perancangan yang telah diuraikan pada babbab sebelumnya, maka pada penelitian ini menghasilkan suatu sistem informasi Knowledge Management System pada bidang pelayanan siswa di SMA satria Nusantara, yang dapat digunakan untuk mempermudah siswa, guru dan staff karyawan dalam mengolah dan mendapatkan pengetahuan kompetensi yang dibutuhkan, untuk menyelesaikan masalah bidang 


\section{Journal of Software Engineering Ampera}

Vol. 1, No. 1, February 2020 e-ISSN: 2775-2488

https://journal-computing.org/index.php/journal-sea/index

pelayanan. Hasil dari penelitian ini akan dituangkan dalam bentuk aplikasi yang mana akan dijalankan pada jaringan localhost menggunakan XAMPP yang nantinya dapat digunakan untuk meningkatkan pelayanan pada SMA Satria Nusantara meliputi pelayanan pendaftaran siswa baru, pelayanan pembayaran iuran SPP dan pembangunan, pelayanan prosedur pengambilan dan legalisir ijazah, pelayanan bimbingan dan konseling

\section{1) Halaman Home Index}

Halaman home index merupakan Halaman utama yang akan menghubungkan beberapa halaman lainnya terdiri dari halaman profil, pelayanan, forum diskusi dan data file dokument.

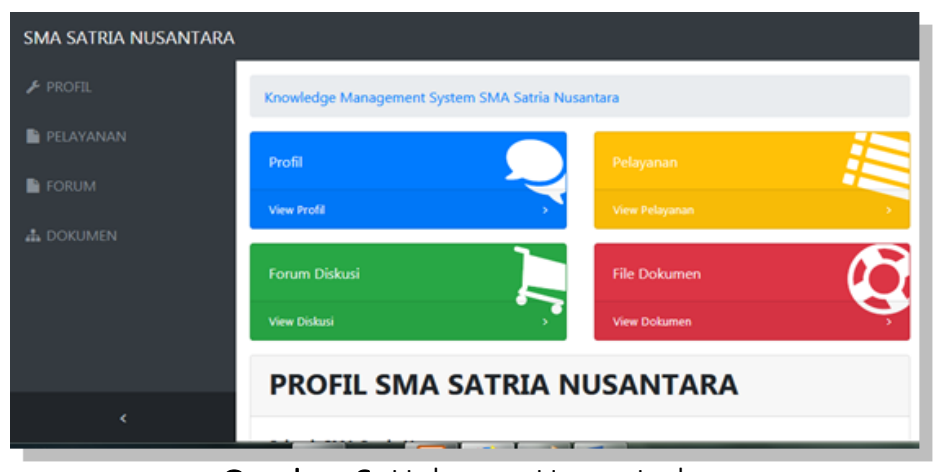

Gambar 6. Halaman Home Index

\section{2) Halaman Pelayanan}

Halaman pelayanan berfungsi untuk menampilkan informasi prosedur pelayanan akademik pada SMA Satria Nusantara terdiri dari pelayanan pendaftaran siswa baru, pelayanan pembayaran iuran SPP dan pembangunan, pelayanan prosedur pengambilan dan legalisir ijazah, pelayanan bimbingan dan konseling.

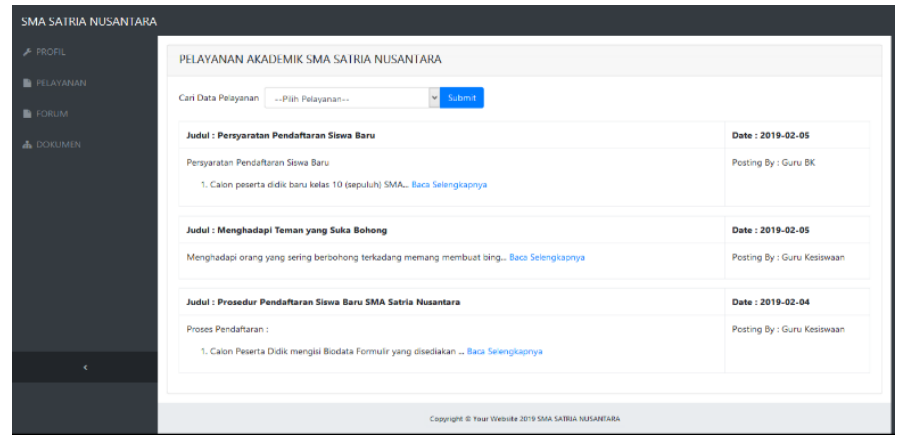

Gambar 7. Halaman Pelayanan 


\section{Journal of Software Engineering Ampera}

Vol. 1, No. 1, February 2020 e-ISSN: 2775-2488

https://journal-computing.org/index.php/journal-sea/index

\section{3) Halaman Forum}

Halaman forum akan digunakan user untuk berkomunikasi terhadap petugas pelayanan melalui forum diskusi, dilakukan dengan menentukan judul topik, kategori pelayanan, nama dan email user. Halaman forum diskusi dapat dilihat pada gambar 8 pada halaman selanjutnya.

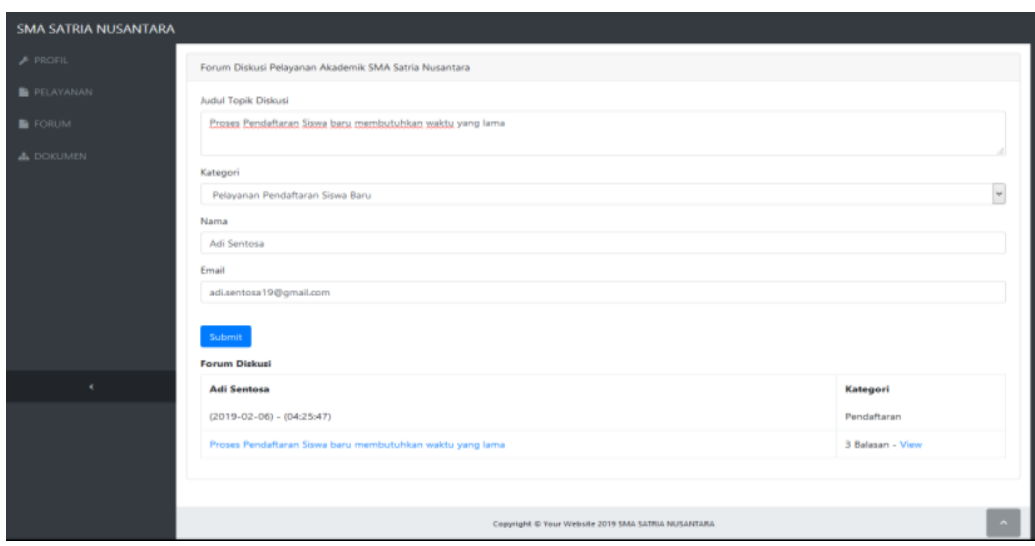

Gambar 8 Halaman Forum

\section{4) Halaman Dokumen}

Pada halaman dibawah ini berfungsi untuk menampilkan file dokumen yang telah diupload oleh petugas pelayanan. Berisikan informasi mengenai pelayanan yang meliputi pelayanan pendaftaran siswa baru, pelayanan pembayaran iuran SPP dan pembangunan, pelayanan prosedur pengambilan dan legalisir ijazah, pelayanan bimbingan dan konseling

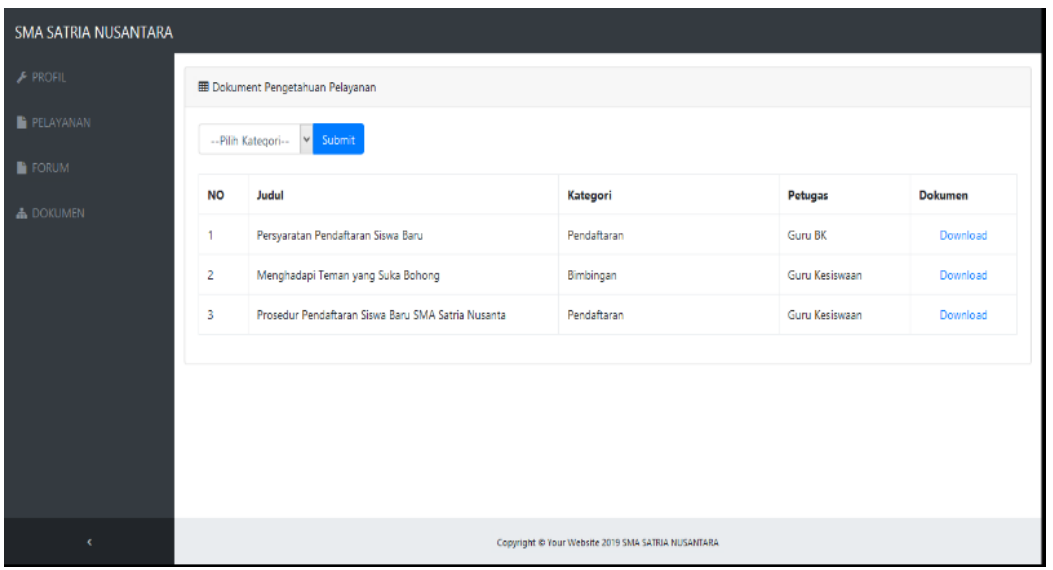

Gambar 9. Halaman Dokumen 


\section{Journal of Software Engineering Ampera}

Vol. 1, No. 1, February 2020 e-ISSN: 2775-2488

https://journal-computing.org/index.php/journal-sea/index

\section{5) Halaman Login}

Halaman form login merupakan Halaman yang akan digunakan user untuk ingin masuk ke menu utama yang berfungsi agar tidak setiap user dapat mengakses sistem ini. Berikut Halaman form login

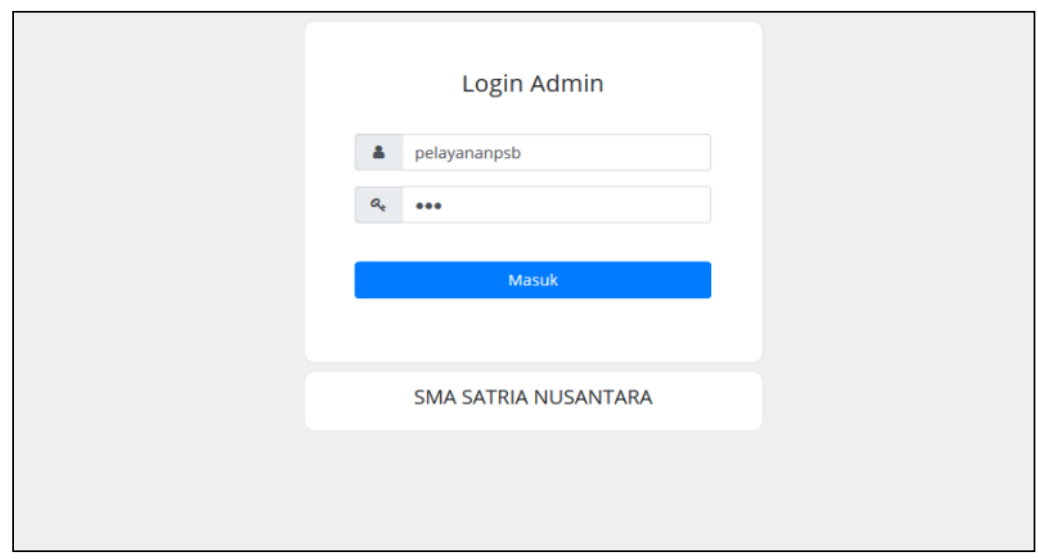

Gambar 10. Halaman Login

\section{6) Halaman Menu admin}

Pada halaman menu utama admin yaitu petugas pelayanan akademik berfungsi untuk mengelola data knowledge tentang pelayanan berisikan halaman-halaman yang saling berhubungan.

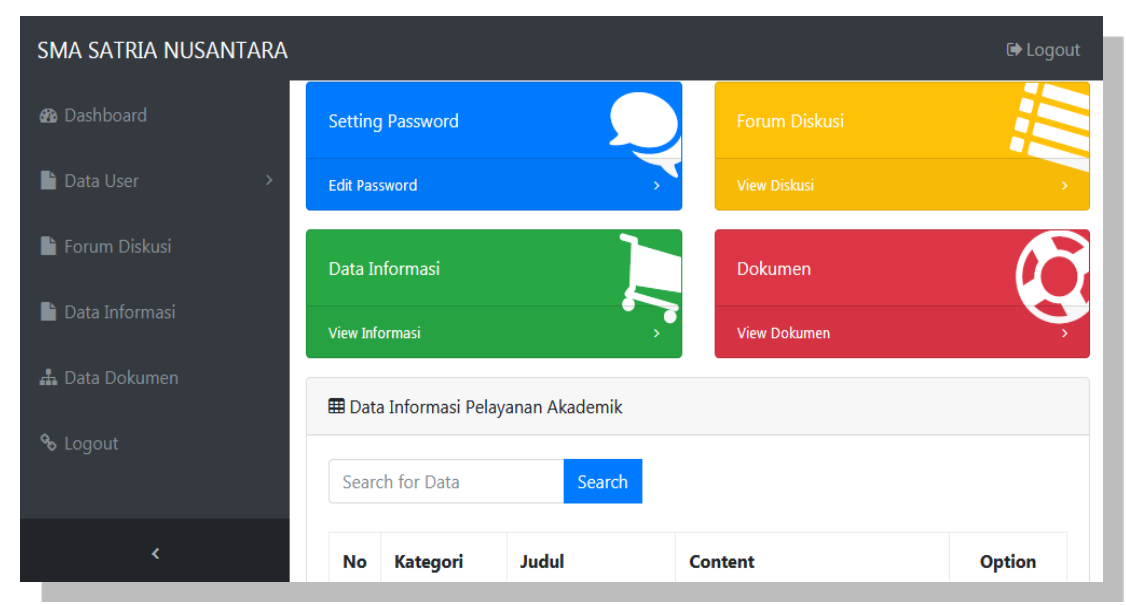

Gambar 11 Halaman Menu admin 


\section{Journal of Software Engineering Ampera}

Vol. 1, No. 1, February 2020 e-ISSN: 2775-2488

https://journal-computing.org/index.php/journal-sea/index

\section{7) Halaman Balasan Diskusi}

Setelah user menentukan topik diskusi, kemudian petugas pelayanan akan menjawab pertanyaan user, melalui form balasan diskusi, yang akan menampilkan informasi beberapa komentar dari user lainnya. Halaman balasan diskusi dapat dilihat pada gambar 12 pada halaman selanjutnya.

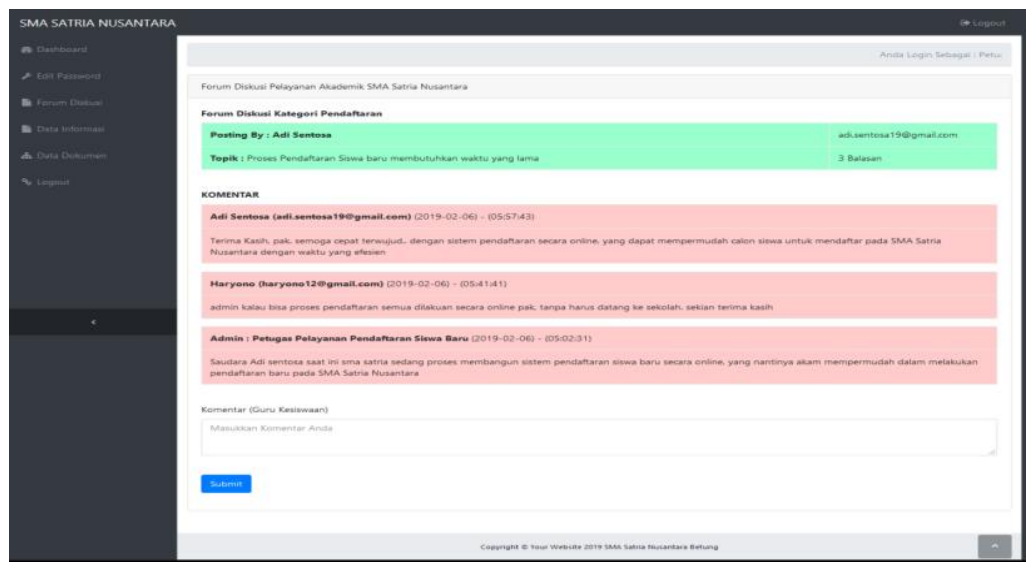

Gambar 12. Halaman Balasan Diskusi

\section{8) Halaman Data Informasi}

Berikut ini halaman data informasi menampilkan informasi prosedur pelayanan akademik dalam bentuk tabel. Berisikan beberapa sistem operasi yaitu entry informasi, upload file dokumen, pencarian informasi, edit dan delete data informasi. Halaman data informasi dapat dilihat pada gmbar 13 pada halaman selanjutnya.

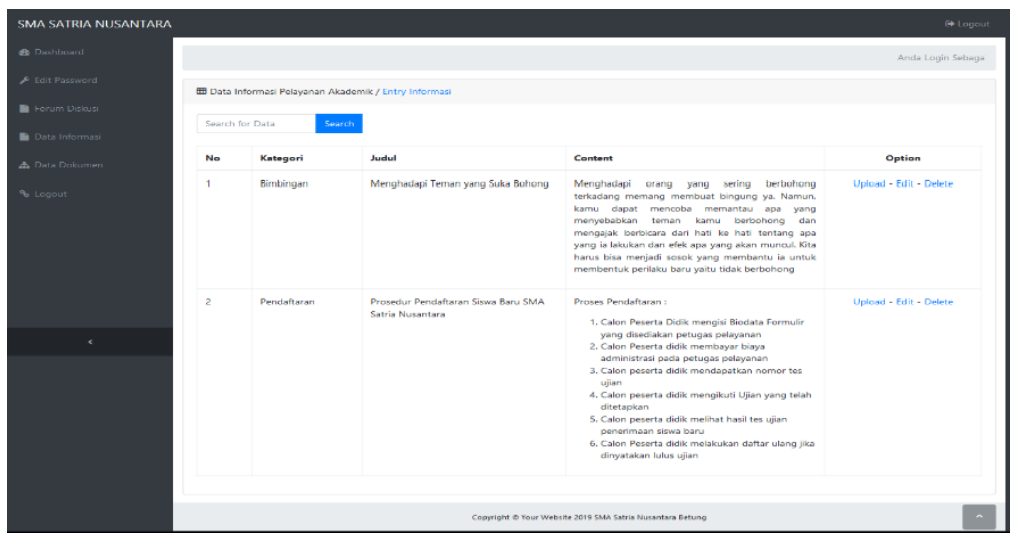

Gambar 13 Halaman data informasi 


\section{Journal of Software Engineering Ampera}

Vol. 1, No. 1, February 2020 e-ISSN: 2775-2488

https://journal-computing.org/index.php/journal-sea/index

\section{9) Halaman Upload Dokumen}

Pada halaman upload dapat ditampilkan melalui halaman data informasi pada halaman diatas, berfungsi untuk memasukkan file dokument dalam format word dan pdf.

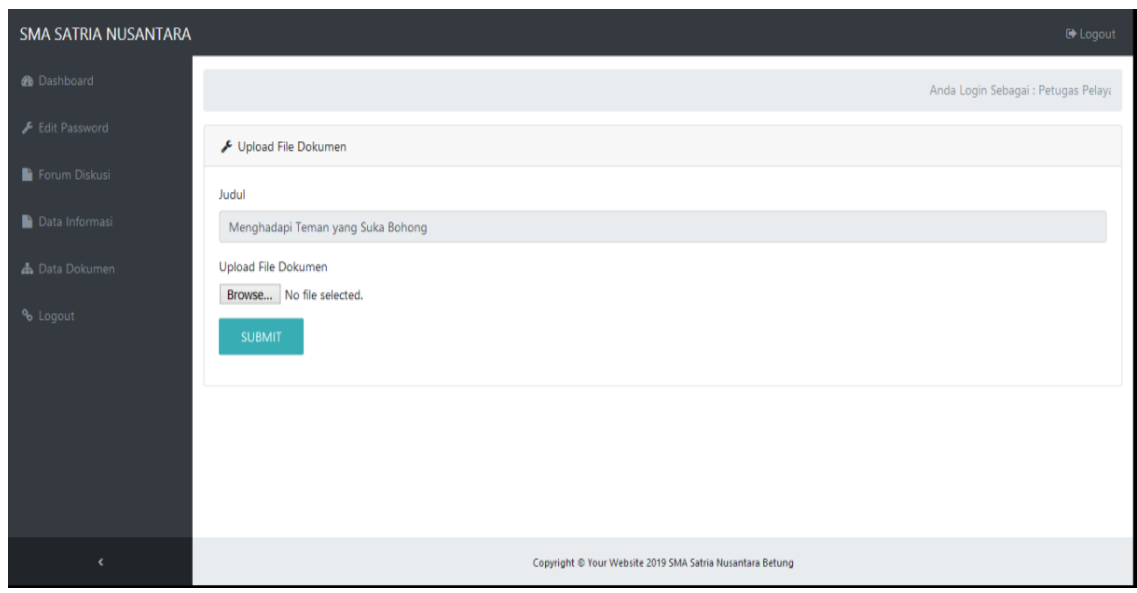

Gambar 14. Halaman Upload Dokumen

\section{KESIMPULAN}

Berdasarkan uraian hasil dan pembahasan yang telah dijelaskan pada bab-bab sebelumnya. Maka penulis menarik beberapa kesimpulan yaitu:

1) Pada penelitian ini menghasilkan sistem yaitu sistem informasi Knowledge Management System pada bidang pelayanan siswa di SMA satria Nusantara dengan pengguna terdiri dari user dan petugas pelayanan meluputi petugas pelayanan pendaftaran siswa baru, pelayanan pembayaran iuran SPP dan pembangunan, pelayanan prosedur pengambilan dan legalisir ijazah, pelayanan bimbingan dan konseling, dimana masing-masing petugas memiliki hak akses terhadap sistem Knowledge Management System.

2) Dengan adanya sistem sistem Knowledge Management System ini, dapat membantu pihak sekolah dalam mempermudah siswa, guru dan staff karyawan dalam memperluas informasi dan sharing tukar pendapat dengan petugas pelayanan yang terjadi di lingkungan SMA Satria Nusantara. 


\section{Journal of Software Engineering Ampera}

Vol. 1, No. 1, February 2020 e-ISSN: 2775-2488

https://journal-computing.org/index.php/journal-sea/index

\section{DAFTAR PUSTAKA}

Fernando. (2012). "Sistem Informasi dan rekayasa perangkat lunak", Graha Ilmu, Yogyakarta.

Fowler, Martin. (2005). "Panduan Singkat Bahasa Pemodelan Objek Standar UML". Andi: Yogyakarta

Jogiyanto, Hartono. (2012). "Analisis \& Desain Sistem Informasi”. Yogyakarta: Andi Offset.

Kadir, Abdul. (2015), "PengenalanSistemInformasi”.Andi Offset. Yogyakarta

Laudon, Kenneth C, Laudon, Jane P. (2002). "Management Information System: Managing the Digital Firm". Upper Saddle River, New Jersey: Prentice Hall, Inc.

Mochamad. Nazir. (2003), "Metode Penelitian". Salemba Empat: Jakarta

Nawawi, Ismail. (2012). "Manajemen Pengetahuan: Teori dan Aplikasi dalam Mewujudkan Daya Saing Organisasi Bisnis dan Publik". Surabaya: Ghalia Indonesia

Paul L, Tobing. (2007). "Knowledge Management: Konsep, ArsitekturdanImplementasi". Yogyakarta: Grahallmu.

Probst, Gilbert et al. (2010). "Managing Knowledge: Building Block for Success. Chichester England": JohnWiley\& Sons Ltd. Baffin Lane.

O’Brien, James A. danMarakas, George M. (2015). "Management Information Systems, 10th Edition". McGraw-Hill/ Irwin, New York

Utomo, S. (2005). "RekayasaPerangkatLunak". Bandung: YramaWidya

Widayana, Lendy. (2005). "Knowledge Management :MeningkatkanDayaSaingBisnis". Jatim: Bayu Media Publishing. 